\title{
THE FLOOD IN VARNA CITY IN JUNE 2014 - \\ A NATURAL OR MAN - MADE DISASTER?
}

DOI: http://dx.doi.org/10.18509/GBP.2018.59

UDC: 627.516:504.4(497.2)

\author{
Daniela Zlatunova \\ Sofia University "St. Kliment Ohridski”, Bulgaria
}

\begin{abstract}
The publication aims to study the flood formation mechanisms of the devastating flood in 2014 in the Varna City, Republic of Bulgaria. Another reason for the study is to improve our understanding of the complex interactions between the factors (natural and anthropogenic) determining the formation and the scale (intensity and territorial scope) of the flood and which turned the natural phenomenon a disaster.

The systemic approach is used to analyse flood formation mechanisms. The spatial analysis method takes a central place in the examination of the flood formation factors and mechanisms, using GIS as a tool for analysis.

The established result of the study is that flood in Varna was caused by the manifestation of the two types of floods - river and pluvial floods. The reasons for turning the natural phenomenon into disaster are related to the home construction in the gully, the great construction density of the neighbourhood, the reduced conduction of the gully and the hydrotechnical facilities. Last but not least, the large number of human casualties is the insufficient awareness of the inhabitants of the flood hazard and the preparedness for an adequate individual response to protection.
\end{abstract}

Keywords: flood formation mechanisms, river flood, pluvial flood, Republic of Bulgaria

\section{INTRODUCTION}

Asparuhovo district of Varna city was flooded on 19.06.2014, by the high wave formed in Temelkovo (Western) Gully. Victims and material damage have been caused. The catchment area of the Temelkovo Gully extends to the Black Sea drainage sub-area and lies to the south of Varna Lake. The Temelkovo Gully springs from a wooded area located to the south of Asparuhovo quarter of Varna, passes through it and flows into a canal that connects the Black Sea with Varna Lake.

The publication aims to study the flood formation mechanisms and improving our understanding of the complex interactions between the factors (natural and anthropogenic) determining the formation and the scale (intensity and territorial scope) of the flood and which turned the natural phenomenon a disaster.

\section{MATERIAL AND METHODS / METHODOLOGY}

Various information has been used to achieve the purpose of the research - spatial data (orthophotomaps, cadastral maps, etc.), map materials, hydro meteorological information, video recordings and TV reports, demographic information and scientific publications related to the topic of the study. 
The systemic approach is used to analyse flood formation mechanisms. The spatial analysis method takes a central place in the examination of the flood formation factors and mechanisms, using GIS as a tool for analysis.

\section{RESULTS AND DISCUSSION}

The flood in Asparuhovo district is a phenomenon that results from the specific combination of natural (climatic and landscape) and anthropogenic (land use) factors in the catchment area of Temelkovo Gully.

\section{Natural factors}

\section{Climatic factors}

The atmosphere over Bulgaria, on 19.06.2014 is highly unstable. The influx of warm and humid air from the sea to the dry land leads to the formation of a meso - cyclone over Eastern Bulgaria. Around $6 \mathrm{pm}$, a massive cloud system starts to develop, which in vertical growth reaches a high altitude (the upper limit of the cloud cover at 21.16 and 12 $\mathrm{km}$ ). It started to rain about midnight on 18.06. 2014, with rainfall continuing almost uninterrupted until about 11 am on 20.06.2014. The total amount of precipitation for this period is $109.2 \mathrm{~mm}$. The largest precipitation is in statinon Varna that was reported in the interval 6-20 pm and in the Asparuhovo district in the interval 3-5 pm. The maximum intensity of the rainfall (within 30 minutes) that was measured at the station Varna (between 16.30 and $17.00 \mathrm{pm}$ ) is $2,31 \mathrm{~mm} / \mathrm{min}$. This is why the precipitation is defined as torrential (intense) rains. In addition, they significantly exceed the monthly precipitation norm (1961 - 1990) for June (239\% of the norm) and the 90th percentile of June's monthly rainfall. The rainfall on 20.06 .2014 is the maximum 24 hours rainfall for June 2014 and exceeds 90th percentile of 24 hours maximum rainfall. It is also the largest recorded for the period 1925 - 2015, as it is more repeatable than once every 50 years. Precipitation falling in the catchment area of the Temelkovo Gully is not an unusual phenomenon for the region of Varna. These precipitation rates are considerably lower than the maximum observed (20.08.1951) to date maximum 24-hour rainfall in Varna $258 \mathrm{~mm}$ and $120 \mathrm{~mm}(3.09 .1999)$.

In this case, the extreme features of rainfall, namely its intensity (strong) and duration (rapid), are of greater importance for the high wave formation in Temelkovo Gully. In Varna station, only for an hour the precipitation reaches $24,5 \mathrm{~mm}$ or $33 \%$ of the roundthe-clock precipitation sum ( $24 \mathrm{~h}$ period) with maximum rainfall intensity (within 30 minutes) $-2.31 \mathrm{~mm} / \mathrm{min}$. The absolute maximum intensity, measured for the same period in Varna city is 2,01 $\mathrm{mm} / \mathrm{min}$. (20.08.1951) In addition, this extreme precipitation falls on the heavily moistened surface, which determinates the formation of a surface runoff (runoff coefficient close to 1.0). It quickly flows into the Temelkovo Gully and forms the high wave.

\section{Geological and hydrogeological structure}

The catchment area of Temelkovo Gully is located in the so called Varna depression. The geological base of the city of Varna, especially in the area of Asparuhovo, is made up of sands with layers of clays, sandstones and rarely conglomerates (Galata geological ensemble, $\mathrm{gNj}$ ). It is characterized by the predominance of yellowish and whitish sands, as layers gray and greenish clays and sandy clays are often found there, rarely lenses and layers of sandstones, sandy and deciduous limestone. The water permeability of the rocks, which is measured by the filtration coefficient, is their most important feature on which 
depends the processes of rainwater filtration and infiltration and the formation of surface runoff. It depends on the physicochemical and mechanical features, such as the mineral and chemical composition, the degree of consistency, the porosity, the density and the origin of the cracks in them and etc. The rocks of the Galata ensemble on this indicator are categorized as medium-to-low permeable rocks ${ }^{26}$ with a filtration coefficient of $5 \mathrm{~m} / \mathrm{d}$ $-5 \mathrm{~m} / \mathrm{d}$. Therefore, the lithological composition of the rock limits the infiltration of the precipitation to a greater depth. Infiltrated rainfall moistens an area of 2 to $4 \mathrm{~m}$ below the surface, which is a factor for the activation of landslides.

\section{Hydrogeological structure}

The hydrogeological structure, which builds the territory of Temelkovo Gully, is the Varna artesian basin, which is characterized by the layered aquifers and complexes. Particularly important is only the highest aquifer formed in the Miocene material of the Galata ensemble, which is included within the scope of the underground water body BG2G000000N019- porosity water in Neogene - Miocene - Galata - Dolen Chiflik. ${ }^{27}$ In the northern coast of the surface, older and relatively less water-permeable rocks of the Rousser ensemble are reported, referring to the underground water body BG2G0000Pg026- porosity water in Paleogene - Eocene Varna-Shabla. According to the information of the Basin Directorate of the Black Sea Region, the water body BG2G000000N019 - porosity water in Neogene - Miocene - Galata - Dolen Chiflik ${ }^{28}$ has an area of 427,91 km and more specifically in the area of "Asparuhovo" it is entirely located above the local erosion base. The predominant nature of groundwater is nonpressurized aquifer. Feeding comes from rainfalls and it is hampered by the soil layer, the disintegration of the relief and the processes of evapotranspiration. In the vertical direction, the filtration properties are highly variable and correspond to the lithological characteristics, such as the presence of clayey deposits that significantly reduce drainage infiltration in depth. Drainage of groundwater is from springs or directly in the river network. Groundwater surface discharge is lithological predetermined - in the contact areas of the aquifer sandy sediments with the clays. For that reason, there are a number of springs located above the local erosion base. They are an important factor for humidification of the slopes and create favorable conditions for the development of land sliding processes. In conclusion, the specific hydrogeological structure and the filtration characteristics of the rocks are a factor for limiting the infiltration of the rainwater in the earth's crust and are a factor for the formation of predominantly surface (slope) runoff. It forms the high wave that flooded in Asparuhovo quarter and the activation of the landslide processes in the urbanized as well as in the non-urbanized part of the quarter.

\section{Geomorphological factors}

The average altitude of the catchment is slightly above $106 \mathrm{~m}$. With largest areas are the height strips of $0-50$ and $50-100 \mathrm{~m}$, which cover the lower part of the gully where Asparuhovo is located, in the middle part of the gully the altitude is in the range 100 $150 \mathrm{~m}(8,9 \%$ of the total area). In the upper part, the height stripes150-200 and 200 $202 \mathrm{~m}$ occupy insignificant areas. Characteristic of the relief are the slopes in the range

\footnotetext{
${ }^{26}$ In accordance with their filtration properties, three types of rocks are separated:

(1) highly permeable with a filtration coefficient $(\mathrm{K})$ of 500 to $10(\mathrm{~m} / \mathrm{d})$;

(2) Medium permeable with a filtration coefficient $(\mathrm{K})$ of 50 to $1(\mathrm{~m} / \mathrm{d})$;

(3) weaknesses to impermeable with a filtration factor $(\mathrm{K})$ of 3 to $0(\mathrm{~m} / \mathrm{d})$.

${ }^{27}$ Designed by the Basin Directorate of Varna, as required by the Framework Directive 2000/60 / EC

${ }^{28}$ Designed by the Basin Directorate of Varna, as required by the Framework Directive 2000/60 / EC
} 
of $0-10^{\circ} \mathrm{C}(77.6 \%$ of the catchment area), $12.8 \%$ of the area has slopes in the range of $20-30^{\circ}$. The territory with slopes in the interval $\left(>30^{\circ}\right)$ occupied the third place in the catchment. An insignificant part of the catchment of the gully has slopes in the range of $10-20^{\circ} \mathrm{C}$. The described relief features create specific runoff conditions. The upper (southern) and middle part of the gully are wider and leveled, while the lower part of the area where Asparuhovo is located is narrowed and highly leveled - from 2 to $5 \mathrm{~m}$ above sea level. The main characteristics of the riverbed that are important for the activation of the torrential processes are deep (up to $30 \mathrm{~m}$ ) and $\mathrm{V}$ - shaped at the top of the gully to $\mathrm{U}$ - shaped near Asparuhovo cross sections. The slopes of the gully are steep $\left(30^{\circ}-45^{\circ}\right)$ and in some places they reach $75^{\circ}$ (at the top of the gully) and decrease to less than $10^{\circ}$ in the area of Asparuhovo (lower part of the gully); a long longitudinal slope (44,9\%o), and in some areas at the beginning and the middle part of the gully it reaches $75 \%$. Unstable lithological composition constituting the riverbed. The significant surface runoff, formed on 19 June 2014, due to the steep slopes, enters the gully at high speed and activates both landslide and collapsing slope processes as well as vertical (deep) erosion. As a result of this process, in the upper part of the gully and on the left tributary, local erosion bases form, forming temporary water basins. At the same time, the riverbed is being dug. (carved out). In the upper and middle part of the gully, new landslides are formed and the old (existing) landslides in the urbanized part of the gully (Asparuhovo district) are activated. The eroded material is actively entrained in the water stream together with the collapsing slope material, thereby forming a muddy mass. It blocks the narrow gully in multiple places and creates conditions for the water to become clogged. When the barrier breaks, as a result of the considerable longitudinal slope of the riverbed, the significant mud water flow, which has a great destructive force, is being transported at a high speed to the Asparuhovo. The special characteristics of the rocks forming the riverbed and the low coefficient of friction due to the highly smooth surface of the bottom of the gully, contribute to the great speed.

Soil cover

In the catchment area of Temelkovo Gully, the soil type of brown and grey forest soils is spread. The soil before the flood is in full saturation due to the continuous and significant precipitation falling in the previous days. The water retaining capacity of this soil type is high - 30-35\%.[4]. Gray forest soils are also characterized by a slow infiltration rate $(\mathrm{K}=0,09-0,1 \mathrm{~m} / 24 \mathrm{~h})$ of precipitation. [5] This combined with the presence of a powerful clay-luminous-metamorphic horizon is a prerequisite for reducing their water conductivity in depth. The dense build-up and asphalting of the streets in Asparuhovo district are an essential factor for the so-called "Soil sealing", which in combination with the significant slopes turns the streets of Asparuhovo in rivers where the water is moving at a very high speed and has a considerable destructive power. The described mechanical and water - physical properties of gray forest soils are an essential factor for the formation of predominantly surface runoff.

Vegetation cover

The vast majority of the catchment area of the Temelkovo (West) Gully is occupied by forests - deciduous, coniferous and mixed. The deciduous forests are mainly represented by oak, honey, hornbeam between the ages of 50 and 70 years and a height of 15-20 m. In the northeastern part of the basin, on a small area are developed coniferous forests represented by black and white pine, atlas cedar, sea pine and others at age 40 years and height between 12 - $14 \mathrm{~m}$. Mixed forests are represented by silver-linden, black pine and hornbeam, hazel. Well-developed is the underbrush represented by hornbeam, honey, 
cherry, oak. [2] The health status of forests before flooding is good (they do not form significant quantities of natural waste - fallen trees and branches which, as a result of the significant surface runoff, contribute to the barrier of the gully).

In terms of their water-regulating role, it is larger in the deciduous forest vegetation, which retains significantly less amount of rainwater (interception). Research shows that deciduous forests retain about $15-25 \%$ of annuals rainfall, while coniferous 27 to $33 \%$ of annual rainfall. [6] However, during the disaster / flood, the water-regulating role of forests was determined by specific weather conditions. On one hand due to the continuous precipitation falling in the period 15.06. - 19.06. 2014 leaves of the trees were wet. On the other hand, precipitation is characterized by a high intensity in a short time (according to witnesses - "water is poured on rods"). The wind speed of $17-18 \mathrm{~m} / \mathrm{s}$, which is a prerequisite for decreasing the water-holding capacity (interception) of the deciduous forests and reaching almost the entire quantity of rainwater to the ground surface, respectively the formation of surface runoff.

\section{Anthropogenic factors}

\section{Spatial Planning}

The expansion of Asparuhovo district took place in the direction of Temelkovo Gully, and over the years, an increasing part of the riverbed was built up. The house built in the bed of the gully, that is to say the "water path" where the impact force of the high wave (mud - stone stream) is greatest, is completely destroyed. At the same time, a high density of construction characterizes the district. This is also the main factor for the large number of casualties and material damage.

\section{Logging and illegal felling of forests}

The use of forest resources is carried out by Territorial Directorate "State Forestry" Varna based on the activities planned in the "Forest plan", 2007. [2] The total amount of harvested timber for the period 2008 - 2014 is 4325,86 cubic meters, as planned in the "Forest plan", 2007 - 5 820, 00 cubic meters. The conclusion is that the use of forest resources in the Temelkovo Gully basin does not cause deforestation; on the contrary, the planned felling maintains and improves the condition of the forests.

In the territory of Territorial Directorate "State Forestry" Varna are registered cases of illegal logging, but the harvested timber is in negligible quantities $\left(33,4 \mathrm{~m}^{3}\right.$ in 2013 and $10,5 \mathrm{~m}^{3}$ in 2014). Therefore, the illegal felling did not affect the state of the forest system. There was no deforestation in the territory of Asparuhovo district and this process have not contributed intensification the torrential processes that took place on 19.06.2017.

Prior to the flood, a planned timber harvest was carried out in the entire catchment area of Temelkovo Gully. However, all issued logging permits order that the way of cleaning up the clearing is through "accumulation or even dispersal of branches in the clearing". "Satisfactory" mark for cleaning procedures has been given in all finding protocols. This means that almost all of the broken branches were scattered or accumulated everywhere. As significant surface runoff is formed, this wood mass is deposited in the gully where it becomes a component of the material that blocks narrow areas of the gully and creates conditions for the water to come clogged and water basins to be formed.

\section{Wastes and unregulated landfills}

Before the flood, Temelkovo Gully is contaminated with construction waste, used tires and mixed household waste.[1] It can be aaccepted that these wastes, together with carried by the water mud mass, whole trees, branches and leaves contributed to the 
partitioning of the gully and the reduction of the water conductivity of the drainage under Perekop Street. Their role in the formation of the high wave, however, is insignificant as it is already formed in a volume much larger than the water conductivity of the drainage under Perekop Street.

\section{Water bodies and hydro technical facilities}

In the outline of Asparuhovo district, the gully is corrected and known as "West guard channel, ,with a purpose to take the gully runoff into channel that connects Varna Lake with Black sea. A culvert is built below Perekop street.The tube culvert at Gravitsa Street is built from two concrete pipes with a diameter of $60 \mathrm{~cm}$. and a length of about $730 \mathrm{~m}$. The culvert is able to conduct a maximum water quantity of about $2 \mathrm{~m}^{3} / \mathrm{s}$, which is negligible. [3] The hydro technical facilities (culvert below Perekop street, tube culrvet at Gravitsa street and West guard channel) have very low conductivity and are unable to take away efficiently even much small water quantities.

\section{Conductivity of the gully}

Before the flood, the bed of the gully in its non-urbanized part is overgrown with trees and bushes. In its narrowest part, two buildings were built. In the urbanized area, the riverbed is narrowed due to the construction of a square. In the past instead of square there was a so called ,natural retention basin" where the water freely spilled and the formed water quantity freely passed through the drainage under Perekop Street without flowing outside the riverbed. The water conductivity of West guard channel is reduced due to poor dimension/sizing on hydro technical facilities (the culvert below Perekop Street and the pipe drainage). It should be emphasized, that with the maximum water quantity of $150 \mathrm{~m}^{3} / \mathrm{s}$ even when properly dimensioned, they could not be effective and contribute to the discharging of the significant mass of water $\left(2.0-2,5 \mathrm{~m}^{3}\right)$ in the Black Sea canal, without water going out of the gully bed.

\section{CONCLUSION AND/ RECOMMENDATIONS}

Most of the Asparuhovo district was flooded as a result of river-type flood with origin Temelkovo and Iztochno Gully. The high wave is formed in the area located in the nonurbanized part as a result of a complex mechanism- blocking the water conductivity through "natural and artificial partitioning"and "reduced water conductivity" of the gullies. In the higher parts of Asparuhovo, the damages of the road pavement and the buildings are resulting from the so - called " "Pluvial" (scattered /slope) flood with a source of torrential intense rainfall, fallen on 19.06.2014. The significant surface water layer formed in the higher parts of Asparuhovo district caused the activation and the appearance of the old landslides located in the urbanized part of Temelkovo and East Gully, which threat residential buildings with devastation and cause a flood-related disaster - the occurrence of landslides.

The natural phenomenon becomes a disaster due to the influence of a number of anthropogenic factors that determine the magnitude (intensity and territorial range) of the disaster. A major factor for the human casualties and material damage is the unregulated construction in Temelkovo Gully and the great density of the build up in neighborhood. The reduced conductivity along the gully is another important factor contributing to the formation of the high wave. Last but not least, the large number of human casualties was caused by the insufficient awareness of the inhabitants about the danger of flooding and the preparedness for an adequate individual response for protection. Staying in the house 
at 68 Gorna Studena Str., despite the fact that the water starts to penetrate through the window and the front door, was fatal for the inhabitants.

\section{REFERENCES}

[1] Finding Protocol No. 004176 / dated 21.03.2013 issued by RIEW - Varna, canal - gull on Gorna Studena Str. (In Bulg.).

[2] Forestry plan, 2007 (In Bulg.).

[3] Hydrological studies for determining the dimensional water quantities for gullies and security channels", company "FOS", 1997 (archive of the municipality) In Bulg.

[4] Penkov, M. Meliorative soil science, Sofia, 1986, pp 56 (In Bulg.).

[5] USDA/NRCS Urban Hydrology for Small Watersheds. TR-55. Technical Release 55.

[6] Ward, R.C., M. Robinson. Principles of Hydrology. McGraw- Hill Publishing Company, 2000, pp 137. 